\title{
VERSITA
}

\section{Voluntary Simplicity - A Path to Sustainable Prosperity}

\author{
Duane Elgin $^{1 *}$
}

${ }^{1}$ Executive director, Great Transition Stories, 200 Bolinas Road, \# 34 Fairfax, CA 94930, USA

KEYWORDS

Simplicity

Simple living

Ecology

Environment

Community

\begin{abstract}
Voluntary simplicity is not about living in poverty; it is about living with balance. This contribution illuminates the pattern of changes that an increasing number of people around the world are making their everyday lives as an active response to the challenges of our times. By embracing a lifeway of simplicity - characterized by a compassionate and ecological consciousness, frugal consumption, and inner development - people can change their lives and, in the process, move the world toward sustainable prosperity.
\end{abstract}

\section{How Shall We Live?}

Time is up! Wake-up alarms are ringing around the world with news ranging from economic breakdowns and the end of cheap oil to climate disruption, crop failures, and famines. The time has arrived for making dramatic changes in how we live. If we act swiftly and voluntarily, we can transform catastrophe into opportunity. Small steps alone will not be sufficient. We require a radical redesign of our urban environments with localized economies, a fundamental overhaul in our energy systems, a more conscious democracy with the strength to make great changes, and much more.

As individuals, are we helpless in the face of such immense challenges? Do we feel there is little we can do? The reality is just the

\footnotetext{
*Contact address: duane@duaneelgin.com (D. Elgin)
} 
opposite - only changes in our individual lives can establish a resilient and strong foundation for a promising future.

The choice facing humanity is described in stark terms by Professor Jared Diamond in his prize-winning book Collapse. He writes that, one way or another, the world's environmental problems will get resolved within a generation:

'The only question is whether they will become resolved in pleasant ways of our own choice, or in unpleasant ways not of our choice, such as warfare, genocide, starvation, disease epidemics, and collapses of societies.' (Diamond 2005: 498).

Our choice as a species is straightforward and profound. We can awaken ourselves from the dream of limitless material growth and actively invent new ways to live within the material limits of the Earth. Or we can continue along our current path of denial and bargaining, using up precious decades, until we slam into an evolutionary wall and so profoundly wound the biosphere and human relations that it cripples humanity's evolutionary possibilities for millennia to come.

One choice is to continue along our current path of increasingly unsustainable consumption, knowing that it leads to a future of ecological ruin. Another choice is to confront the reality of unsustainable consumer societies, bring this taboo topic squarely into our public conversation, and search for realistic alternatives. This is an extremely difficult public conversation because it challenges the underlying paradigm of materialism and the self-image of nations who are identified as consumer societies. Nonetheless, the global dialogue regarding how we are all to live on this Earth has begun in earnest. To illustrate, world leaders in science, religion, and politics were calling, in 2008, for a new path to sustainability and ecological sanity. In politics the premier of China called upon rich countries 'to shoulder the duty and responsibility to tackle climate change and alter their unsustainable lifestyle'. In religion, the pope criticized developed nations for 'squandering the world's resources in order to fuel an insatiable consumption'. In science, the world's leading climatologist, James Hansen, 
warned that without a dramatic reduction in greenhouse gas emissions, we will create a dramatically different and far less hospitable planet for the people of the Earth.

After two hundred or more years of material growth, we are confronted with an unyielding question: If the material consumption of a fraction of humanity is already harming the planet, is there an alternative path that enables all of humanity to live more lightly upon the Earth while experiencing a higher quality of life? This question reaches deep into humanity's psyche and soul. Transforming our levels and patterns of consumption requires our looking directly into how we create our sense of identity and seek our happiness. Furthermore, because the ecological challenges we face are global in nature, so too must be our conversation concerning how we are to share the Earth with one another and the rest of life.

Despite the necessity for change, it is hard to believe we humans will turn away from the lure of materialism and growth until we collectively recognize this path leads, as professor Diamond warns, to 'warfare, genocide, starvation, disease, and collapse'. A turn also requires compelling visions of the future that act as beacons for our social imagination. We do not yet carry in our social imagination clear visions of the opportunities afforded by new forms of growth. Instead of visualizing how material limitation can draw out new levels of community and cooperation, many people see a life of greater 'simplicity' as a path of sacrifice and regress.

Living within the limits that the Earth can sustain raises fundamental questions: Can we live more lightly on the material side of life while living with greater satisfaction and meaning on the non-material side of life? In short, is simplicity a life of sacrifice?

\section{Simplicity Is Not Sacrifice}

Simplicity that is voluntary - consciously chosen, deliberate, and intentional - supports a higher quality of life. There are many reasons why people choose lives of greater simplicity. Some people feel their lives are out of 
balance and feel too busy to connect meaningfully with friends, nature, and even family. Other people seek a more harmonious relationship with the Earth - the land, air and water. For different reasons, we can develop a way of life that is rich with satisfactions far beyond those offered by consumerist lifestyles. Simplicity is not a confining lifestyle but a liberating way of life that contributes to the well-being of the world and future generations.

Contrary to media myths, consumerism offers lives of sacrifice while simplicity offers lives of opportunity. Simplicity creates the opportunity for greater fulfilment in work, meaningful connection with others, feelings of kinship with all life, and awe of a living universe. This is a rich way of life that offers a compelling alternative to the stress, busyness, and alienation of the modern era. Nonetheless, the mainstream media in many societies are driven by consumerism and have been reluctant to explore the promise of simplicity because it threatens the engine of economic growth that is their lifeblood.

\section{Three Views of Simplicity}

I find it ironic that a life-way of simplicity that can take us into an opportunity-filled future is often portrayed in the mass media as primitive or regressive way of life that turns away from progress. Here are three major ways that I see the idea of simplicity presented in today's popular media:

Crude or Regressive Simplicity: The mainstream media often shows simplicity as a path of regress instead of progress. Simplicity is frequently presented as anti-technology and anti-innovation, a backward-looking way of life that seeks a romantic return to a bygone era. A regressive simplicity is often portrayed as a utopian, back-to-nature movement with families leaving the stresses of an urban life in favour of living in the woods, or on a farm, or in a recreational vehicle, or on a boat. This is a stereotypical view of a crudely simple lifestyle - a throwback to an earlier time and more primitive condition - with no indoor toilet, no phone, no computer, no television, and no car. No thanks! Seen in this way, simplicity is a cartoon 
lifestyle that seems naive, disconnected, and irrelevant - an approach to living that can be easily dismissed as impractical and unworkable. Regarding simplicity as regressive and primitive makes it easier to embrace a 'business as usual' approach to living in the world.

Cosmetic or Superficial Simplicity: In recent years, a different view of simplicity has begun to appear - a cosmetic simplicity that attempts to cover over deep defects in our modern ways of living by giving the appearance of meaningful change. Shallow simplicity assumes that green technologies such as fuel-efficient cars, fluorescent light bulbs, and recycling - will fix our problems, give us breathing room, and allow us to continue pretty much as we have in the past without requiring that we make fundamental changes in how we live and work. Cosmetic simplicity puts green lipstick on our unsustainable lives to give them the outward appearance of health and happiness. A superficial simplicity gives a false sense of security by implying that small measures will solve great difficulties and allow us to continue along our current path of growth for decades or more.

Deep or Conscious Simplicity: Occasionally presented in the mass media and poorly understood by the general public is a conscious simplicity that represents a deep, graceful, and sophisticated transformation in our ways of living - the work we do, the transportation we use, the homes and neighbourhoods in which we live, the food we eat, the clothes we wear, and much more. A sophisticated and graceful simplicity seeks to heal our relationship with the Earth, with one another, and with the sacred universe. Conscious simplicity is not simple. This is a life way that is growing and flowering with a garden of expressions. Deep simplicity fits aesthetically and sustainably into the real world of the twenty-first century.

Few people would voluntarily go through the difficulty of fundamentally restructuring their manner of living and working if they thought they could tighten their belts and wait for things to return to 'normal'. A majority of people will shift their ways of living only when it is unmistakably clear that we must make dramatic and lasting changes. Has the world reached a point of no return and crossed a threshold where a shift 
toward the simple prosperity of green lifestyles is the new 'normal'?

\section{What Kind of Simplicity Fits Our World?}

Although human societies have confronted major challenges throughout history, our era is unique (see Elgin 2010: 114-134). To summarize, here are four world-changing trends that illustrate what an exceptional time we are living in now - and how our lives will be profoundly different in the near future:

Peak Oil-only one time will we use up all of the world's reserves of oil. We have already used up roughly half of all the oil - the half that is easiest and cheapest to get - and global demand is skyrocketing. The price of oil will escalate and depress the global economy until the world can shift to renewable energy sources.

Climate Change - only one time will we melt the world's ice caps and glaciers and radically destabilize the planet's climate. We are creating a new Earth for future generations and risking monumental crop failures and famines in this generation.

Overpopulation - only one time will we so unconsciously overpopulate the Earth with billions of people beyond the regenerative capacity of the land, water, and air ecosystems.

Species Extinction - only one time will we cause the extinction of a third or more of all animal and plant species. The integrity of the web of life is one of the clearest measures of the health of the Earth. We are destroying large portions of the biosphere and putting at risk the very foundations of our existence.

Never before has the human family been on the verge of devastating the Earth's biosphere and crippling its ecological foundations for countless generations to come. The circle has closed and there is no escape. The Earth is a single, tightly interconnected system. Both the natural ecology of the Earth and the social ecology of human relations are being placed at profound risk. We confront far more than individual 'problems'. We are 
moving into an intertwined, world-system crisis involving every aspect of life. In this generation we meet fundamental questions head-on: Who are we? What kind of journey are we on as a human community? How are we to live together on this increasingly small Earth?

If we are to maintain the integrity of the Earth as a living system, we require deep and creative changes in our overall levels and patterns of living and consuming. Simplicity is not an alternative lifestyle for a marginal few. It is a creative choice for the mainstream majority, particularly in developed nations. If we are to pull together as a human community, it will be crucial for people in affluent nations to embrace a deep and sophisticated simplicity as a foundation for sustainability. Simplicity is simultaneously a personal choice, a community choice, a national choice, and a species choice.

\section{Many Names for a Shared Understanding}

The movement toward simplicity is part of a 'leaderless revolution' underway around the world. This revolution's principle concerns are building a sustainable future with the Earth, a harmonious relationship with one another, and a sacred relationship with the nature and the universe. This is a self-organizing movement in which people are consciously taking charge of their lives. It is a promising demonstration of people taking responsibility for how their lives connect with the Earth and the future. Many of these pioneers have been working at the grass-roots level for several decades, often feeling alone, not realizing that scattered through society are others like themselves numbering in the millions.

In his book Blessed Unrest (2007), Paul Hawken describes the largely invisible rise of the world's largest movement working for environmental health and social justice, involving more than a million organizations around the world. He writes:

'Across the planet, groups ranging from ad hoc neighbourhood associations to well-funded international organizations are confronting issues like the destruction of the environment, the 
abuses of free-market fundamentalism, social injustice, and the loss of indigenous cultures. They share no orthodoxy and follow no single charismatic leader, yet they are organizing from the bottom up and coalescing into larger networks to achieve their goals - most urgently, ecological sustainability.'1

Because a concern for ecological sustainability is so widely shared, there are many ways of describing more sustainable and meaningful ways of living. There is no special virtue to the phrase 'voluntary simplicity'. Because this is a leaderless revolution in living, people are inventing as they go including inventing words and phrases to characterize their approach to living. Other phrases in common use that offer an alternative to 'voluntary simplicity' are for example: green life-ways, earth-friendly living, sustainable lifestyles, simple prosperity, and others. In part they mean the same thing, sometimes they put different emphasis on what is to be discussed. Whatever we call this approach to living, a grass-roots movement with many names is growing around the world with three overriding and intertwined concerns - how are we to live sustainably on the Earth, in harmony with one another, and in communion with the universe?

\section{Misconceptions about the Simple Life}

Four misconceptions about the simple life are so common that they deserve special attention. These are equating simplicity with poverty, rural living, ugly living, and economic stagnation.

Simplicity Means Poverty - although some spiritual traditions have advocated a life of extreme renunciation, it is misleading and inaccurate to equate simplicity with poverty. My awakening to the harsh reality of poverty began on my father's farm in Idaho, where I worked with people who lived on the edge of subsistence. I remember one fall harvest when I was about ten years old in the early 1950s. We were harvesting a forty-acre field of lettuce, and a crew of twenty or so migrant labourers arrived to go to

\footnotetext{
${ }^{1}$ Summary taken from the press materials that accompanied his book.
} 
work. I still recall a family of three - a father, mother, and a daughter about my age - who drove their old Mercury sedan down the dusty road into our farm. They parked in the field and, with solemn faces, worked through the day doing piece labour - getting paid for the number of crates of lettuce they filled. At the end of the day they received their few dollars of wages as a family, earning roughly sixty-five cents an hour. That evening I returned to the fields with my father to check on the storage of the crates of lettuce and found the family parked at the edge of the field, sitting against the side of their car, and eating an evening meal that consisted of a loaf of white bread, a few slices of lunch meat, and a small jar of mayonnaise. I wondered how they managed to work all day on such a limited meal but asked no questions. When I arrived for work the following morning, they got out of their car where they had slept the night and began working another day. After they had repeated this cycle for three days, the harvest was finished and they left. This was just one of innumerable personal encounters with poverty.

Over the next fifteen years, as I worked in the fields each summer, I gradually came to realize that most of the people working beside me did not know whether, in another week or month, their needs for food and shelter would be met by their meagre salary. As I worked side by side with these fine people, I saw that poverty has a very human face - one that is very different from 'simplicity'. Poverty is involuntary and debilitating, whereas simplicity is voluntary and enabling. Poverty is mean and degrading to the human spirit, whereas a life of conscious simplicity can have both a beauty and a functional integrity that elevates the human spirit. Involuntary poverty generates a sense of helplessness, passivity, and despair, whereas purposeful simplicity fosters a sense of personal empowerment, creative engagement, and opportunity. Historically those choosing a simpler life have sought the golden mean-a creative and aesthetic balance between poverty and excess. Instead of placing primary emphasis on material riches, they have sought to develop, with balance, the invisible wealth of experiential riches. 
Simplicity Means Rural Living - in the popular imagination there is a tendency to equate the simple life with Thoreau's cabin in the woods by Walden Pond and to assume that people must live an isolated and rural existence. Interestingly, Thoreau was not a hermit during his stay at Walden Pond. His famous cabin was roughly a mile from the town of Concord, and every day or two he would walk into town. His cabin was so close to a nearby highway that he could smell the pipe smoke of passing travellers. Thoreau wrote that he had 'more visitors while I lived in the woods than any other period of my life' (quoted in Shi 1985: 145). The romanticized image of rural living does not fit the modern reality, as a majority of persons choosing a life of conscious simplicity do not live in the backwoods or rural settings; they live in cities and suburbs. While green living brings with it a reverence for nature that does not require moving to a rural setting. Instead of a 'back to the land' movement, it is much more accurate to describe this as a 'make the most of wherever you are' movement - and increasingly that means adapting ourselves creatively to a rapidly changing world in the context of big cities and suburbs.

Simplicity Means Ugly Living - the simple life is sometimes viewed as a primitive approach to living that advocates a barren plainness and denies the value of beauty and aesthetics. While the Puritans, for example, were suspicious of the arts, many other advocates of simplicity have seen it as essential for revealing the natural beauty of things. Many who adopt a simpler life would surely agree with Pablo Picasso, who said that 'art is the elimination of the unnecessary'. The influential architect Frank Lloyd Wright was an advocate of an 'organic simplicity' that integrates function with beauty and eliminates the superfluous. In his architecture a building's interior and exterior blend into an organic whole, and the building, in turn, blends harmoniously with the natural environment (Shi 1985: 145). Rather than involving a denial of beauty, simplicity liberates the aesthetic sense by freeing things from artificial encumbrances. From a spiritual perspective, simplicity removes the obscuring clutter and discloses the spirit that infuses all things. 
Simplicity Means Economic Stagnation - some worry that if a significant number of people simplify their lives it will reduce demand for consumer goods and, in turn, produce unemployment and economic stagnation. While it is true that the level and patterns of personal consumption would shift in a society that values green living, a robust economy can flourish that embraces sustainability. Although the consumer sector and material goods would contract, the service and public sectors (education, healthcare, and urban renewal) would expand dramatically. When we look around at the condition of the world, we see a huge number of unmet needs: caring for elderly, restoring the environment, educating illiterate and unskilled youth, repair of decaying roads and infrastructure, providing health care, creating community markets and local enterprises, retrofitting the urban landscape for sustainability, and many more. Because there are an enormous number of unmet needs, there are an equally large number of purposeful and satisfying jobs waiting to get done. The difficulty is that in many industrialized nations there is such an overwhelming emphasis placed on individual consumption that it has resulted in the neglect of work that promotes public well being. There will be no shortage of employment opportunities in an Earth-friendly economy. In moving toward simpler ways of living and a needs-oriented economy that does not artificially inflate consumer wants, an abundance of meaningful and satisfying jobs will become available along with the ways to pay for them.

It is important to acknowledge these stereotypes because they make a simpler life seem impractical and unapproachable and thereby reinforce the feeling that nothing can be done to respond to our critical world situation. To move from denial to action, it is vital to have an accurate understanding of a life way of conscious simplicity and its growing relevance for the human journey.

\section{Growth of Green Living}

When I did the research for the first edition of Voluntary Simplicity (Elgin 
1981) in the late 1970s, the world was a different place. Thirty years ago, humanity was still blessed with cheap oil, a stable climate, and a moderate population compared to resources. This produced an era of easy abundance and, in this setting; the simple life looked like a path of regress - a needless turn away from the 'good life'. However, three decades later - with the end of cheap oil, a destabilized climate, and crop failures and famines combined with a massive and growing global population that overwhelms available resources - the context for understanding simplicity is fundamentally different. The easy abundance of the past is being replaced by forced frugality.

Meanwhile a growing number of people are empowering themselves to invent alternative approaches to living that are more sustainable and satisfying. In the United States and around the world there is clear evidence of a shift underway as people take personal responsibility for contributing to the well being of the world.

Although leaderless, this self-organizing movement for sustainability is growing rapidly around the world. In the United States and a dozen or so other 'postmodern' nations (including Europe, Japan, and Australia), a movement toward green living has grown from a minuscule subculture in the 1960s to a respected part of the mainstream culture in the early 2000s. Glossy magazines now sell the simple life and green living from newsstands across the United States, and it has become a popular theme on major television talk shows. Based upon three decades of research, I estimate that as of 2008, roughly 20 percent of the U.S. adult population, or approximately 40 million people, are consciously crafting Earth-friendly or green ways of living. These life-way pioneers are providing the critical mass of invention at the grass roots level that could enable the larger society to move swiftly to alternative ways and approaches to living that sustainable.

These changes are not confined to the United States and Europe. Around the world, people are awakening to the sanity of simplicity as a path to sustainability. Global surveys show that majorities of people support environmental protection and human development, two key themes 
accompanying life-ways of simplicity.

The following surveys illustrate how simplicity and sustainability have become an integral part of a mainstream culture involving millions of people. Gerald Celente, president of the Trends Research Institute, reported in 1997 on how the voluntary simplicity trend is growing throughout the industrialized world:

'Never before in the Institute's 17 years of tracking has a societal trend grown so quickly, spread so broadly and been embraced so eagerly' (Celente 1997).

The following surveys provide further evidence that a life way of conscious simplicity, with a characteristic pattern of values, is emerging as a significant trend in the world.

Yearning for Balance - A 1995 survey of Americans' commissioned by the Merck Family Fund found that respondents' deepest aspirations are non-material. For example, when asked what would make them much more satisfied with their lives, 66 percent said 'if I were able to spend more time with my family and friends', and only 19 percent said 'if I had a bigger house or apartment'. Twenty-eight percent of the survey respondents said that, in the last five years, they had voluntarily made changes in their lives that resulted in making less money, such as reducing work hours, changing to a lower-paying job, or even quitting work. The most frequent reasons given for voluntarily downshifting were: 1 ) Wanting a more balanced life (68 percent), 2) Wanting more time (66 percent), and 3) Wanting a less stressful life (63 percent). Had it been worth it? Eighty-seven percent of the downshifters described themselves as happy with the change. In summing up the survey's findings, the report states:

'People express a strong desire for a greater sense of balance in their lives - not to repudiate material gain, but to bring it more into proportion with the non-material rewards of life.' (The Harwood Group 1995).

World Values Survey - Ronald Inglehart, global coordinator of the survey, concluded that, over the last three decades, a major shift in values 
has been occurring in a cluster of a dozen or so nations, primarily in the United States, Canada, and Northern Europe. He calls this change the 'postmodern shift'. In these societies, emphasis is shifting from economic achievement to postmaterialist values that emphasize individual selfexpression, subjective well-being, and quality of life. At the same time, people in these nations are placing less emphasis on organized religion, and more on discovering their inner sense of meaning and purpose in life (see: Inglehart, Foa, Peterson and Welzel 2008; Inglehart 2008).

Health of the Planet Survey - in 1993, the Gallup organization conducted in 24 nations this a landmark global survey of attitudes toward the environment (Dunlap 1994: 125). In writing about the survey, its director Dr. Riley E. Dunlap concluded that there is 'virtually world-wide citizen awareness that our planet is indeed in poor health, and great concern for its future well-being'. The survey found that residents of poorer and wealthier nations express nearly equal concern about the health of the planet. Majorities in most of the nations surveyed gave environmental protection a higher priority than economic growth, and said that they were willing to pay higher prices for that protection. There was little evidence of the poor blaming the rich for environmental problems, or vice versa. Instead, there seems to be a mature and widespread acceptance of mutual responsibility. When asked who is 'more responsible for today's environmental problems in the world', the most frequent response was that industrialized and developing countries are 'both equally responsible'.

World Environmental Law Survey - the largest environmental survey ever conducted was done in the spring of 1998 for the International Environmental Monitor. Involving more than 35,000 respondents in 30 countries, the survey found that 'majorities of people in the world's most populous countries want sharper teeth put into laws to protect the environment'. Majorities in 28 of the 30 countries surveyed (ranging from 91 percent in Greece to 54 percent in India) said that environmental laws as currently applied in their country 'don't go far enough'. The survey report concludes: 
'Overall, these findings will serve as a wake-up call to national governments and private corporations to get moving on environmental issues or get bitten by their citizens and consumers who will not stand for inaction on what they see as key survival issues.' (Environics International 1998).

Global surveys also show there is virtually worldwide citizen awareness that our planet is indeed in poor health and great public concern for its future well being. It makes little difference whether people live in poorer and wealthier nations - everyone expressed nearly equal concern for the health of the planet.

\section{The Choice for Simplicity}

The circle has closed. The Earth is a single system and we humans have reached beyond its regenerative capacity. It is of the highest urgency that we invent new ways of living that are sustainable. The starting gun of history has already gone off and the time for creative action has arrived. With lifestyles of conscious simplicity, we can seek our riches in caring families and friendships, reverence for nature, meaningful work, exuberant play, social contribution, collaboration across generations, local community, and creative arts. With conscious simplicity, we can seek lives that are rich with experiences, satisfaction, and learning rather than packed with things. With these new ingredients in the lives of our civilizations, we can redefine progress, awaken a new social consciousness, and establish a realistic foundation for a sustainable and promising future.

\section{Acknowledgement:}

Taken from: Duane Elgin. 2010. Voluntary Simplicity. Toward a Way of Life That Is Outwardly Simple, Inwardly Rich. Second revised edition. New York: HarperCollins Publication. 1-24 (abridged and slight revised). 


\section{References:}

Diamond, Jared M. 2005. Collapse: How Societies Choose to Fail or Succeed. New York: Viking Press.

Dunlap, Riley E. 1994. "International Attitudes towards Environment and Development." In Green Globe Yearbook of International Co-operation on Environment and Development 1994, edited by Helge Ole Bergesen and Georg Parmann, 115-126. Oxford; New York: Oxford University Press.

Elgin, Duane. 2010. Voluntary Simplicity: Toward a Way of Life That Is Outwardly Simple, Inwardly Rich. Third Edition. New York: HarperCollins Publication.

Elgin, Duane. 1981. Voluntary Simplicity: Toward a Way of Life That Is Outwardly Simple, Inwardly Rich. First Edition. New York: HarperCollins Publication.

Environics International. 1998. "The Coming Green Wave. Global Public Opinion on the Environment. The 1998 International Environmental Monitor Survey". Presentation at the World Bank. Toronto: Environics International.

Hawken, Paul. 2007. Blessed Unrest: How the Largest Movement in the World Came into Being, and Why No One Saw It Coming. New York: Viking.

Inglehart, Ronald, Roberto Foa, Christopher Peterson, and Christian Welzel. 2008. “Development, Freedom, and Rising Happiness: A Global Perspective (19812007)." Perspectives on Psychological Science 3 (4): 264-285.

Inglehart, Ronald F. 2008. "Changing Values among Western Publics from 1970 to 2006." West European Politics 31 (1-2): 130-146.

Shi, David E. 1985. The Simple Life: Plain Living and High Thinking in American Culture. New York: Oxford University Press.

The Harwood Group. 1995. "Yearning for Balance Views of Americans on Consumption, Materialism, and the Environment July 1995". Takoma Park, Md: Merck Family Fund. 